\title{
Differences of Some Chemicals and Physical Properties of Winter Wheat Grain of Mealy and Vitreous Appearance
}

\author{
I. KONOPKA ${ }^{1}$, M. TAŃSKA ${ }^{1}$ and S. KONOPKA ${ }^{2}$ \\ ${ }^{1}$ Chair of Food Plant Chemistry and Processing, Faculty of Food Sciences, \\ University of Warmia and Mazury in Olsztyn, Poland \\ ${ }^{2}$ Department of Working Machine and Methodology of Research, Faculty of Technical Sciences, \\ University of Warmia and Mazury in Olsztyn, Poland \\ (Received 18 June 2014; Accepted 4 September 2014; \\ Communicated by F. Békés)
}

\begin{abstract}
Many wheat species and cultivars, independent of genetic markers of hardness, can produce grain with a vitreous, mealy or mixed appearance. This study analyzed selected chemical and physical differences between kernels with a vitreous and mealy appearance, hand-picked from grain of four winter wheat cultivars cultivated in Poland. Separated fractions were examined for protein content and composition, friabilin presence, carotenoids and total phenolic compounds content, specific kernel density, hardness, as well as kernel surface color. It was found that the ratio of vitreous kernels in the cultivars ranged from $39.18 \%$ to $76.28 \%$. Vitreous kernels were darker, slightly heavier and harder than mealy kernels. Additionally, these kernels were more abundant in proteins (an average increase of $2.13 \%$, with variation among cultivars from $0.71 \%$ to $2.89 \%$ ). This type of kernels was also richer in phenolic compounds (on average by $4.02 \%$ ) and less abundant in carotenoids (on average by $4.53 \%$ ). Mealy (softer) kernels fractured to a finer flour.
\end{abstract}

Keywords: endosperm vitreousness, mealiness, gluten proteins, kernel density, hardness

\section{Introduction}

Wheat cultivars produce grain in which fully vitreous and mealy, or kernels with mixed endosperm structure exist (Horrobin et al. 2003). So-called "piebald" or "yellow berry" kernels can occur in both durum and hexaploid wheat, with mealy and vitreous zones in a sharply-defined area (Dexter et al. 1989). Evers and Bechtel (1988) explained mealy (starchy, chalky, opaque, soft) endosperm as a result of light scattering at the air-starch and air-protein interfaces. Later studies showed that vitreousness is related to the endosperm microstructure (Greffeuille et al. 2006) as well as to kernel color and its mechanical properties (Peterson et al. 2001; Konopka et al. 2005). Soft endosperm is usually linked with a chalky-opaque appearance, and hard endosperm is linked with a glassy-vitreous appearance. Although the vitreousness of endosperm tissue is more typical of hard wheat,

\footnotetext{
* Corresponding author; E-mail: m.tanska@uwm.edu.pl
} 
soft wheat cultivars may also produce cohesive hard sections. Morris et al. (2008) found large variations in endosperm microstructure from kernel-to-kernel within pure cultivars of soft, hard and durum wheats. Such variability can also be affected by the vegetation conditions, especially by fertilization (Samson et al. 2005) and climate (Evers and Bechtel 1988). For example, when a soft cultivar of wheat is grown under optimum conditions, it produces vitreous kernels and, in contrast, many hard types of wheat produce opaque/mealy kernels (Pasha et al. 2010). Kernel vitreousness has been found to generally increase with nitrogen fertilization supply (Farm Facts 1997) and can be declined by damp conditions before grain harvest (Sandhu et al. 2009).

It was initially thought that starchy and vitreous zones within the endosperm of "piebald" kernels were similar in protein content and composition (Dexter et al. 1989). In a later study, Samson et al. (2005) showed that vitreous kernels are of a higher density, higher protein content and preferentially accumulate gliadins instead of glutenins. According to cited authors "piebald" kernels were an indicator of nitrogen deficit during vegetation and their starchy/soft appearance was associated with a protein content of up to $9.7 \%$ and a gliadin/glutenin ratio of up to 0.85 . However, in a recent study by Morris and Beecher (2012), it was found that near-isogenic lines in soft white spring wheat (which lack the distal portion of chromosome 5D short arm) can produce both vitreous, non-vitreous and mixed kernels, with vitreous and non-vitreous kernels very similar in protein content and kernel density. Additionally, the cited authors concluded that the 5DS gene(s) control the manner in which the endosperm develops, i.e. whether it is vitreous or non-vitreous, as well as kernel hardness.

Although the issue of grain quality with a different mealiness/vitreousness has been studied for many years, existing data on the technological quality of both endosperm microstructure types mainly concern protein variation and are still ambiguous. This study was conducted to show the variation of protein content and composition between mealy and vitreous kernels inside the grain of common winter wheat cultivars. In addition to protein analyses, the present study is also focused on comparing other properties that are mutually related to kernel mealiness/vitreousness, such as phenolic compounds, carotenoids, kernel color and hardness, as well as specific kernel density. This knowledge could be utilized both to confirm the differences of technological/nutritional quality of vitreous and mealy kernels and to show the possibility of their separation.

\section{Materials and Methods}

\section{Sample preparation}

Kernels visually classified as vitreous and mealy inside the grain of four commercial common winter wheat cultivars: Skagen, Olivin, Ludwig, and Muszelka of moisture content approx. to $10 \pm 0.5 \%$ (wet basis) were used. Used grain samples differed in potential baking value, from the highest value estimated as E/A for Skagen, through A value for Olivin and Ludwig and A/B value for Muszelka cultivar, respectively (E, A, B - extra, quality and bread wheat according to Polish Standards, respectively). Initially, whole grain sam- 
ple was tested for particle size index. In next step kernels of vitreous, mealy and mixed appearance were hand-picked from $100 \mathrm{~g}$ of sample and each fraction was weighted in order to determine its ratio in grain mass. In further experiments only grain classified as vitreous (V) and mealy (M) has been utilized (Fig. S1*). Separated fractions have been tested for protein content and composition, moisture, total carotenoids and phenolic compounds content, friabilin presence, kernel specific density, color of kernel surface, hardness of endosperm and characteristics of granulation of flour after milling (the last analysis was done only for one cultivar).

\section{Basic methods}

The moisture content was determined using the PN-EN ISO 712:2012P method. Particle size index, done according to Williams and Sobering (1986) method, was used for endosperm hardness classification. Kernel density was calculated as a ratio of single kernel mass and apparent volume $\left(\mathrm{g} / \mathrm{cm}^{3}\right)$ using toluene pycnometer method (Markowski et al. 2013 ) with an accuracy of weight of $0.001 \mathrm{~g}$. Friabilin (indirect marker of genetic softness) was tested using monoclonal antibody in Durotest ${ }^{\mathbb{B}} \mathrm{S}$ (R-BIOFARM RHONE LTD). Flour granulation was measured by $10 \mathrm{~min}$. sifting with the use of SZ-1 laboratory sifter (Research Institute of Bakery Industry, Bydgoszcz, Poland) with meshes of 60, 120, 150, 200, $240 \mu \mathrm{m}$.

\section{Proteins}

Proteins were analyzed with RP-HPLC technique using the solvent system developed by Wieser et al. (1998). Before analyses grain was milled in a laboratory mill type IKA A10 (Labortechnik, Germany). The chromatographic separation was carried out on a Hewlett-Packard apparatus series 1050: RP-18 Vydac 218TP54 column with $5 \mathrm{~mm}$ bead size and $300 \AA$ pore size, $250 \times 4.6 \mathrm{~mm}$; a Zorbax $300 \mathrm{SB}-\mathrm{C} 18$ pre-column, $4.6 \times 12.5 \mathrm{~mm}$; a column temperature of $45^{\circ} \mathrm{C}$, a mobile phase flow rate of $1 \mathrm{ml} / \mathrm{min}$, and an injection volume of $20 \mathrm{ml}$. A two-component gradient was used. A component: 0 min 75\%, 5 min 65\%, $10 \min 50 \%, 17 \min 25 \%, 18 \min 15 \%$ and $19 \min 75 \%$. The first component (A) was water with $0.1 \%$ of TFA, and the second (B) was ACN with $0.1 \%$ of TFA. The spectra were determined by a diode-array detector (HP 1050). Quantification of proteins was done by UV absorbance at $210 \mathrm{~nm}$. The results were expressed as miliabsorbance units $\times$ second $(\mathrm{mAU} \times \mathrm{s})$. The identification of protein subunits was based on their retention times and the second derivative of their UV spectra according to Konopka et al. (2007). Differences between samples have been highlighted by subtracting chromatogram signal of mealy sample from chromatogram signal of vitreous sample (inside cultivar), separately for each protein fraction.

\section{Carotenoids}

Carotenoids were extracted by water-saturated $n$-butanol, and determined spectrophotometrically according to Kaneko et al. (1997). Absorbance was measured at the wavelength

\footnotetext{
* Further details about the Electronic Supplementary Material (ESM) can be found at the end of the article.
} 
of $449 \mathrm{~nm}$ (maximum of lutein absorption). The measurements were carried out with a UNICAM UV/Vis UV2 spectrophotometer (ATI Unicam, Cambridge, UK). Carotenoid content was presented as mg of lutein per $\mathrm{g}$ of a sample dry mass.

\section{Total phenolic compounds}

Total polyphenols extraction was preceded by alkaline hydrolysis of wheat samples with $2 \mathrm{~N} \mathrm{NaOH} \times 4 \mathrm{~h}$ at room temperature. After hydrolysis, the mixture was neutralized $(6 \mathrm{~N}$ $\mathrm{HCl}$ ) and evaporated to dryness. Released phenolic compounds were extracted by the use of $80 \%$ methanol and determined spectrophotometrically. The color reaction was carried out by adding $0.5 \mathrm{~mL}$ of Folin-Ciocalteau reagent, $3 \mathrm{~mL}$ of $14 \%$ of sodium carbonate and $6.5 \mathrm{~mL}$ of distilled water to the polyphenols extract. After being mixed, the solutions were left for $60 \mathrm{~min}$ and their absorbance was then measured against the reagent sample (without the phenolics extract) at the wavelength of $720 \mathrm{~nm}$, with a UNICAM UV/Vis UV2 spectrophotometer. The content of phenolic compounds was expressed as $\mathrm{mg}$ of D-catechine equivalent in $1 \mathrm{~g}$ of a sample dry mass.

\section{Kernel colour}

The color of the kernel surface was measured using digital image analysis (DIA) for kernels arranged with the ventral side down. The images were acquired by a high resolution, low-noise CCD Nikon DXM-1200 color camera and analyzed by LUCIA G v. 4.8 software. The frame grabber was at a resolution of $1280 \times 1024$ pixels. The kernels were examined from a distance (lens to object) of $13 \mathrm{~cm}$. The light source was a Kaiser RB 5004 HF - High Frequency Daylight Copy Light set with $4 \times 36 \mathrm{~W}$ fluorescent light tubes (color temperature about $5400^{\circ} \mathrm{K}$ ) (Kaiser Fototechnik GmbH \& Co. KG, Germany). Color analyzes were performed on 60 samples of vitreous and mealy kernels. The results are presented in an HSI (H-hue, S-saturation, and I-intensity) color space, where $\mathrm{H}$ is expressed in degrees and $\mathrm{S}$ and $\mathrm{I}$ in percentages. Before analyzes, the calibration to a standard white reflective plate was done.

\section{Endosperm hardness}

Hardness was determined by using an indentation test based on method described by Konopka et al. (2005). Indentation was carried out on a Universal Testing Machine (UTM) Instron 4301 (Instron Corporation, Canton, Massachusetts, USA) by compressing a steel needle $(0.55 \mathrm{~mm}$ in diameter) into the centre of a flat surface of the endosperm to a depth of $0.3 \mathrm{~mm}$ at a rate of $0.5 \mathrm{~mm} / \mathrm{min}$. Research samples were identical as in above described color analyses (60 samples). The maximum force $(\mathrm{N})$ of compression was taken as the hardness.

\section{Statistical analyses}

The intra-cultivar differences between samples of different endosperm appearance were determined with Duncan tests. The effects of cultivar, the type of kernel endosperm appearance and their interactions were determined using a two-factorial variance analysis 
with Wilks tests. The data were analyzed using STATISTICA v.10 software (StatSoft, Inc.). The calculations were performed at a significance level of $P=0.05$.

\section{Results}

Main characteristics of tested wheat cultivar samples

Based on particle size index (Table S1), used cultivars were classified as hard (Skagen and Olivin) or medium hard (Ludwig and Muszelka). In the grain of Skagen, Ludwig and Olivin cultivars, vitreous kernels dominated, with a share from $63.15 \%$ to $76.28 \%$. In contrast, in the Muszelka cultivar, kernels classified as mealy and mixed accounted for $60.82 \%$ of the grain mass. A monoclonal antibody test of the separated fractions showed the presence of friabilins in all samples, with a similar concentration in both V and M kernels (Fig. S2).

\section{Protein variability between vitreous and mealy kernels}

Grain protein content varied from $11.61 \%$ to $15.67 \%$ (Table 1) and was affected by cultivar and endosperm type to a comparable degree (Table S2). Vitreous kernels were approx. $2 \%$ more abundant in total proteins $(12.60 \%$ versus $14.73 \%)$, with the highest difference $(2.89 \%)$ inside kernels of the Skagen cultivar and the lowest $(0.71 \%)$ for the Ludwig cultivar. The RP-HPLC separated ca. 60 protein peaks in total (Fig. S3). Generally, the albumin and globulin fraction constituted from $9.80 \%$ to $13.51 \%$, gliadins from $45.65 \%$ to $50.05 \%$ and glutenins from $38.30 \%$ to $42.54 \%$ of the total protein. Subtracting chromatogram signals of mealy and vitreous samples showed the main quantity differences between fractions of used cultivars, while non-specific peaks were observed. Generally, vitreous kernels were significantly richer in each protein subunits, with the highest average increase of HMW glutenins $(24.12 \%)$ and $\alpha / \beta$ gliadins $(21.14 \%)$. The type of endosperm mostly affected the albumin/globulin fraction and HMW glutenins (with $71.58 \%$ and $62.92 \%$ of explained variance, respectively). In contrast, the cultivar effect was dominant for the content of $\Omega$ gliadins (88.63\% of explained variance) and LMW glutenins (63.48\% of explained variance). Other protein fractions were in a similar way affected by the main tested experimental effects.

Our results showed that the Gli-to-Glu ratio was significantly affected by cultivar (37.11\% of explained variance) and the interaction of cultivar $\times$ type of endosperm effects (36.30\% of explained variance), with a significant impact of other unexplained factors. The Gli-to-Glu ratio varied from 1.08 to 1.31. In two cultivars (Skagen and Muszelka), the increase in total gliadins was higher than the increase in total glutenins, which resulted in an increase in the Gli-to-Glu ratio. An opposite effect was observed for Ludwig and Olivin cultivars, in which vitreous kernels were slightly more abundant in glutenins. However, the overall observed variations between vitreous and mealy kernels were not high (on average, a $2 \%$ change) and should not significantly affect the elastic-viscous properties of the gluten matrix. 


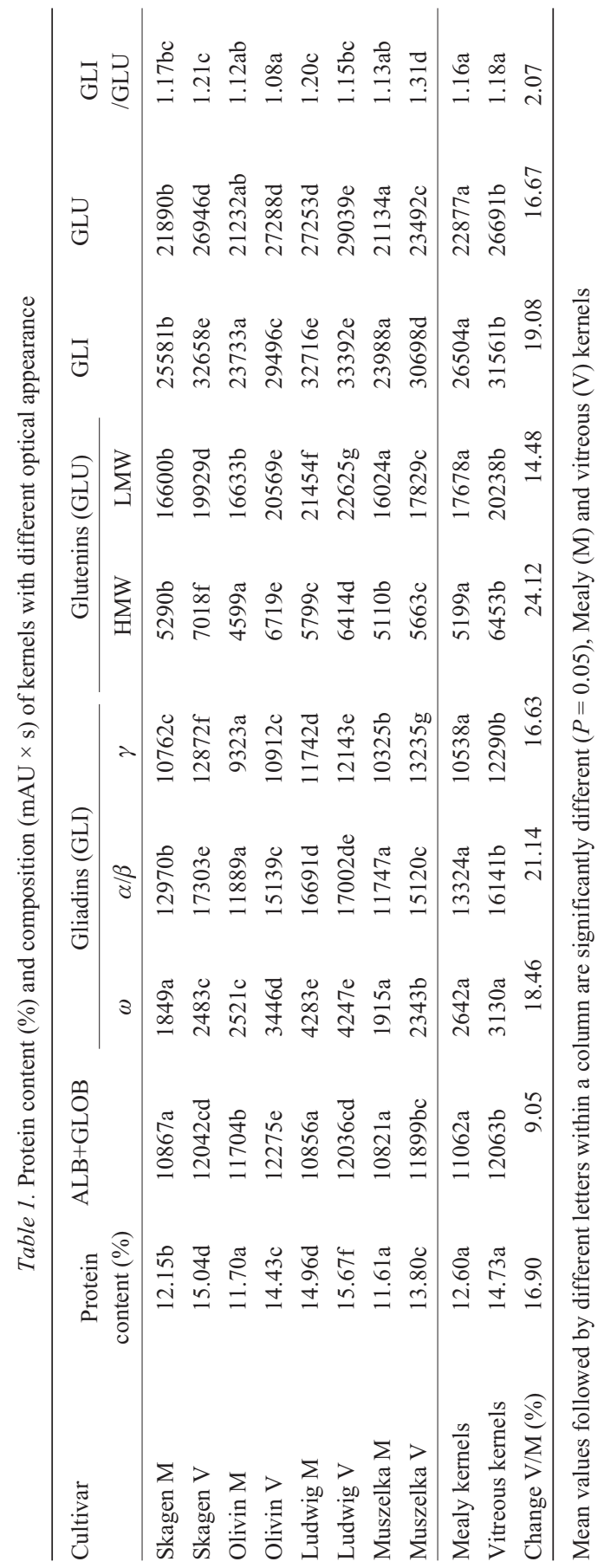




\section{Comparison of other features between vitreous and mealy kernels}

Vitreous kernels inside Skagen, Ludwig and Olivin cultivars were of a slightly lower moisture content (on average, approx. 4\%), and higher density (approx. 5\%) than that of mealy kernels, while in the Muszelka cultivar, moisture content and kernel density were practically the same for both endosperm structures (Table 2). Endosperm hardness of mealy samples was significantly lower than that of vitreous kernels and this feature was mainly cultivar-dependent (52.99\% of explained variance - Table S2), with the lowest and the highest variation for Muszelka and Olivin cultivars, respectively. Characteristics of flour granulation (only one cultivar tested - Muszelka) showed that in flour from vitreous kernels the fraction with a diameter of approx. $170 \mu \mathrm{m}$ prevailed, while flour from mealy kernels was mainly composed of fine particles with a diameter of $90 \mu \mathrm{m}$ (Fig. S4).

Kernel surface color was only slightly affected by cultivar, with hue $(\mathrm{H})$ and intensity (I) values partly affected by the type of endosperm microstructure (up to $28.25 \%$ of explained variance). Generally, in vitreous kernels the hue was shifted from red to orange and the color intensity was up to $7 \%$ lower than in mealy kernels. This indicates minor discoloration of the seed coat of mealy kernels, which can be related to their lower proteins content (Table 1) and changes in grain pigments (Table 2). It was found that mealy kernels were less abundant in phenolic compounds (on average by $4.02 \%$ ), and at the same time richer in carotenoids (on average by $4.53 \%$ ). However, both of these groups of pigments were mostly related to cultivar effect (up to $93.27 \%$ of explained variance for carotenoid content - Table S2).

\section{Discussion}

In the analyzed wheat grain samples kernels with both a vitreous, mealy and mixed appearance were found, and the ratio of these endosperm types varied between cultivars. Although the used cultivars were not tested for genetic markers of hardness/softness, in a study by Langer and Salmanowicz (2009), two of them (Ludwig and Olivin) were genetically classified as soft. The soft genetic character of used cultivars can probably be deduced from the presence of friabilin, which had a similar concentration in vitreous and mealy kernels. This group of proteins is generally abundant in starch granules in grain with a soft character and is scarce on starch isolated from hard grain (Greenblatt et al. 1995). The softer character (in terms of technological properties) of mealy kernels was confirmed by an analysis of flour granulation after milling two extreme fractions of the Muszelka cultivar. It is well known that differences in the characteristics of the cell walls and the interaction of storage macropolymers with small molecules on interfaces affects grain milling (Pasha et al. 2010). Soft endosperm fractures more easily and gives a higher content of fine flour, which was found for mealy kernels of the Muszelka cultivar. According to Langer and Salmanowicz (2009), the majority of Polish cultivars (60 from 69 studied trials) genetically represent endosperm softness (with an approx. equal quantity of Pina-D1a and Pinb-D1a alleles (wild-type) and Pina-D1a and Pinb-D1b alleles). Despite this, they are usually classified as "mixed" using the SKCS system. A similar 


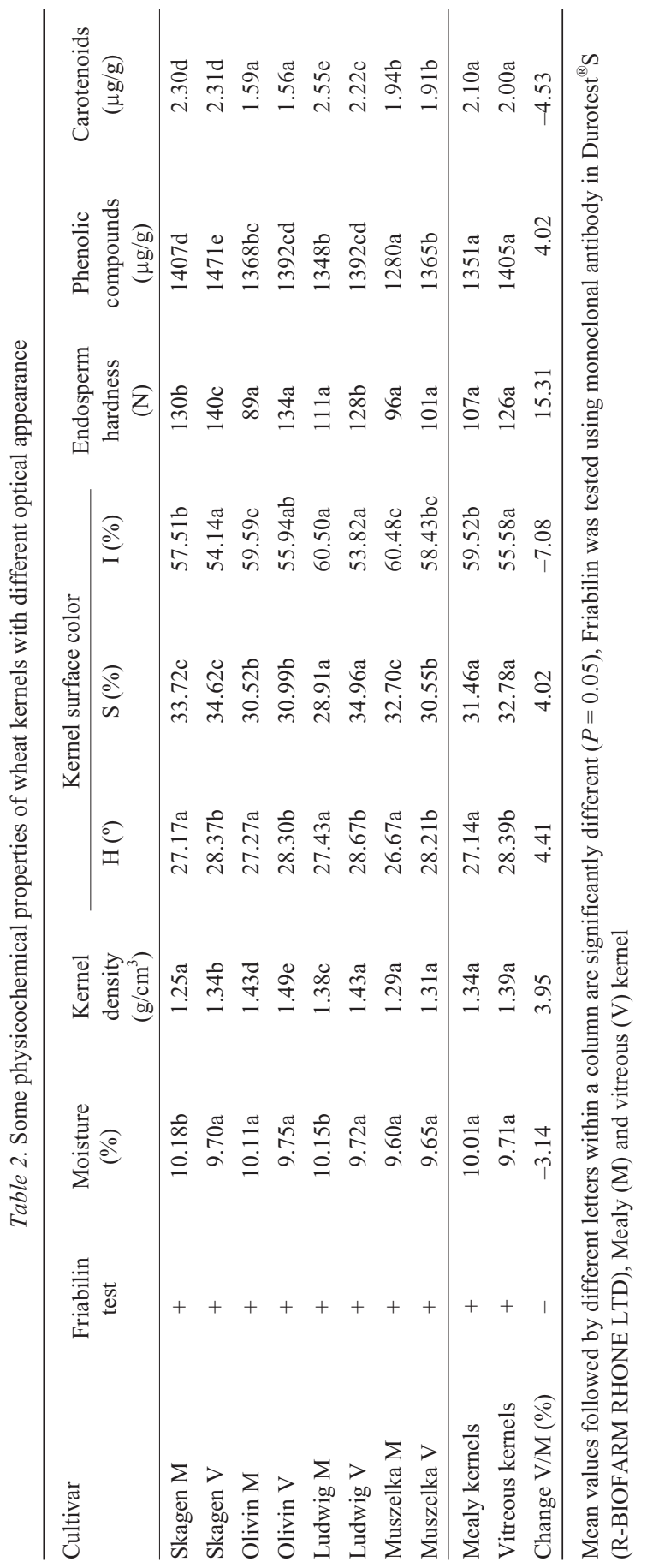


inconsistency of genetic and technological grain softness/hardness properties was observed by Salmanowicz et al. (2012). This generally points to the crucial impact of growing conditions on grain quality, especially for some sensitive wheat genotypes (Mladenov et al. 2012).

Our study showed that vitreous kernels were significantly more abundant in total protein. Samson et al. (2005) found a similar phenomenon among four cultivars of durum wheat (grown with five nitrogen levels at four locations and two years) in which the average total protein content was 1.5 -fold higher for vitreous than for mealy kernels. According to these authors, the total protein content of mealy durum endosperm rarely exceeded $9.7 \%$. Our study showed that the type of endosperm microstructure mostly affected the content of albumins/globulins and HMW glutenins, while Samson et al. (2005) concluded that the vitreousness/mealiness of durum wheat grain is mostly related to $\alpha, \beta$ and $\gamma$ gliadins and the albumins/globulins content. However, in the case of hard red spring wheat grain the content of vitreous kernels is positively correlated with SDS-unextractable HMW proteins (Ohm et al. 2010). Variation of subunits between gliadin and glutenin proteins in mealy/vitreous kernels can affect the Gli-to-Glu ratio, which is an important indicator of grain technological/baking quality. In our study it varied between cultivar samples from 1.08 to 1.31 , and was similar to that presented by Singh et al. (2001), Shewry and Halford (2002), Konopka et al. (2007), and Gil-Humanes et al. (2012). According to Samson et al. (2005), the Gli-to-Glu ratio of vitreous endosperm in durum wheat was higher than 0.85 in more than $98 \%$ of the samples.

It was also found that vitreous kernels were slightly heavier than that of mealy kernels. This is in agreement with the results of Dobraszczyk et al. (2002) and Samson et al. (2005) who showed that the density of durum vitreous endosperm was significantly higher than that of mealy samples, with differences reaching up to $0.13 \mathrm{mg} / \mathrm{mm}^{3}$. In our study, the noted differences were substantially smaller, with the highest $\left(0.09 \mathrm{mg} / \mathrm{mm}^{3}\right)$ noted for the Skagen cultivar. Independent of the main cultivar effect vitreous kernels were also evaluated as harder than mealy kernels. It may be a result of their higher protein content and density, or a lower moisture content. Recently Ohm et al. $(2009 ; 2010)$ reported that both in soft winter and hard red spring wheats kernel hardness variation is mainly related to gliadins.

Vitreous kernels were darker and more abundant in total phenolic compounds, while mealy kernels accumulated a slightly higher content of carotenoids and had a slightly higher moisture content (measured in a state of equilibrium with relative air humidity). Previous studies showed that kernel color highly correlates with proteins (Peterson et al. 2001; Konopka et al. 2005), grain phenolics (Klepacka et al. 2002; Lukow et al. 2012) and carotenoids content (Humphries et al. 2004; Lukow et al. 2012).

Summarizing the results it may be concluded that grain vitreousness/mealiness determines both its nutritional value (protein content and composition, grain pigments) and some physical features (endosperm hardness, kernel density and color). These findings may be useful to control and optimize grain processing (e.g. tempering, milling, and steaming processes) and its utilization. The results show the possibility of separating of kernels with a vitreous and mealy endosperm microstructure using color and/or density 
sorters. Vitreous kernels separated from genetically soft grain are chemically and physically similar to genetically hard grain. This grain may be utilized as an enhancer in grain blends, or as a raw material for pasta and groats production.

\section{Acknowledgement}

The study was financially supported by the Ministry of Scientific Research within the framework of grant no. N N312 201439.

\section{References}

Dexter, J.E., Marchylo, B.A., MacGregor, A.W., Tkachuk, R. 1989. The structure and protein composition of vitreous, piebald and starchy durum wheat kernels. J. Cereal Sci. 10:19-32.

Dobraszczyk, B.J., Whitworth, M.B., Vincent, J.F.V., Khan, A.A. 2002. Single kernel wheat hardness and fracture properties in relation to density and the modelling of fracture in wheat endosperm. J. Cereal Sci. 35:245-263.

Evers, A.D., Bechtel, D.B. 1988. Microscopic structure of the wheat grain. In: Pomeranz, Y. (ed.), Wheat: Chemistry and Technology. American Association of Cereal Chemists, Minnesota, USA, pp. 47-95.

Farm Facts. 1997. Managing wheat for protein premium. Saskatchewan Agriculture and Food, http://www.agriculture.gov.sk.ca

Gil-Humanes, J., Pistón, F., Rosell, C.M., Barro, F. 2012. Significant down-regulation of $\gamma$-gliadins has minor effect on gluten and starch properties of bread wheat. J. Cereal Sci. 56:161-170.

Greenblatt, G.A., Bettge, A.D., Morris, C.F. 1995. Relationship between endosperm texture and the occurrence of friabilin and bound polar lipids on wheat starch. Cereal Chem. 72:172-176.

Greffeuille, V., Abecassis, J., Rousset, M., Oury, F.X., Faye, A., Bar L’Helgouach, C., Lullien-Pellerin, V. 2006. Grain characterization and milling behaviour of near-isogenic lines differing by hardness. Theor. Appl. Genet. 114:1-12.

Horrobin, D.J., Landman, K.A., Ryder, L. 2003. Interior and surface color development during wheat grain steaming. J. Food Eng. 57:33-43.

Humphries, J.M., Graham, R.D., Mares, D.J. 2004. Application of reflectance color measurement to the estimation of carotene and lutein content in wheat and triticale. J. Cereal Sci. 40:151-159.

Kaneko, S., Nagamine, T., Yamada, T. 1995. Esterification of endosperm lutein with fatty acids during the storage of wheat seeds. Biosci. Biotech. Bioch. 59:1-4.

Klepacka, J., Fornal, Ł., Konopka, S., Choszcz, D. 2002. Relations between ferulic acid content in wheat coat, and milling quality and color of grain. Electronic J. of Polish Agricultural Universities 5:15, http://www.ejpau.media.pl/volume5/issue2/food/art-15.html

Konopka, I., Kozirok, W., Tańska, M. 2005. Wheat endosperm hardness. Part I. Relationships to colour of kernel cross-section. Eur. Food Res. Technol. 220:11-19.

Konopka, I., Tańska, M., Pszczółkowska, A., Fordoński, G., Kozirok, W., Olszewski, J. 2007. The effect of water stress on wheat kernel size, color and protein composition. Pol. J. Natur. Sci. 22:157-171.

Langer, M., Salmanowicz, B.P. 2009. Identification of puroindoline alleles in Polish wheat cultivars by molecular markers. Biul. IHAR 253:93-100.

Lukow, O., Suchy, J., Adams, K., Brown, D., DePauw, R., Fox, S., Hatcher, D., Humphreys, G., McCaig, T., White, N. 2012. Effect of solar radiation, plant maturity and post-harvest treatment on the color and phenolic and carotenoids content in seed of red and white Canadian wheat. J. Cell Plant Sci. 3:1-13.

Markowski, M., Żuk-Gołaszewska, K., Kwiatkowski, D. 2013. Influence of variety on selected physical and mechanical properties of wheat. Ind. Crops Prod. 47:113-117.

Mladenov, V., Banjac, B., Krishna, A., Milosević, M. 2012. Relation of grain protein content and some agronomic traits in European cultivars of winter wheat. Cereal Res. Commun. 40:532-541.

Morris, C.F., Beecher, B.S. 2012. The distal portion of the short arm of wheat (Triticum aestivum L.) chromosome 5D controls endosperm vitreosity and grain hardness. Theor. Appl. Genet. 125:247-254. 
Morris, C.F., Bettge, A.D. Pitts, M.J., King, G.E., Pecka, K., McCluskey, P.J. 2008. Compressive strength of wheat endosperm: comparison of endosperm bricks to the single kernel characterization system. Cereal Chem. 85:359-365.

Ohm, J.B., Ross, A.S., Peterson, C.J., Morris, C.F. 2009. Relationships of quality characteristics with size-exclusion HPLC chromatogram of protein extract in soft white winter wheats. Cereal Chem. 86:197-203.

Ohm, J.B., Hareland, G., Simsek, S., Seabourn, B., Maghirang, E., Dowell, F. 2010. Molecular weight distribution of proteins in hard red spring wheat: Relationship to quality parameters and intra sample uniformity. Cereal Chem. 87:553-560.

Pasha, I., Anjum, F.M., Morris, C.F. 2010. Grain hardness: A major determinant of wheat quality. Food Sci. Technol. Int. 16:511-522.

Peterson, C.J., Shelton, D.R., Martin, T.J., Sears, R.G., Williams, E., Graybosch, R.A. 2001. Grain color stability and classification of hard white wheat in the U.S. Euphytica 119:101-106.

Salmanowicz, B.P., Adamski, T., Surma, M., Kaczmarek, Z., Krystkowiak, K., Kuczyńska, A., Banaszak, Z., Ługowska B., Majcher M., Obuchowski, W. 2012. The relationship between grain hardness, dough mixing parameters and bread-making quality in winter wheat. Int. J. Mol. Sci. 13:4186-4201.

Samson, M.-F., Mabille, F., Chéret, R., Abécassis, J., Morel, M.-H. 2005. Mechanical and physicochemical characterization of vitreous and mealy durum wheat endosperm. Cereal Chem. 82:81-87.

Sandhu, K., Manthey, F.A., Elias, E.M. 2009. High relative humidity affects vitreousness of durum wheat [Triticum turgidum L. var. durum (Desf)]. Cereal Res. Commun. 37:269-275.

Shewry, P.R., Halford, N.G. 2002. Cereal seed storage proteins: Structures, properties and role in grain utilization. J. Exp. Botany 53:947-958.

Singh, J., Blundell, M., Tanner, G., Skerritt, J.H. 2001. Albumin and globulin proteins of wheat our: immunological and N-terminal sequence characterization. J. Cereal Sci. 34:85-103.

Wieser, H., Antes, S., Seilmeier, W. 1998. Quantitative determination of gluten protein types in wheat flour by reversed-phase high-performance liquid chromatography. Cereal Chem. 75:644-650.

Williams, P.C., Sobering, D.C. 1986. Attempts at standardization of hardness testing of wheat. I. The grinding/sieving (particle size index) method. Cereal Foods World 31:362-364.

\section{Electronic Supplementary Material (ESM)}

Electronic Supplementary Material (ESM) associated with this article can be found at the website of CRC at http://www.akademiai.com/content/120427/

Electronic Supplementary Table S1. Hardness and vitreousness/mealiness of kernels within analyzed grain samples

Electronic Supplementary Table S2. Variance components (\%) of studied wheat grain features in relation to cultivar (C) and endosperm microstructure type (T)

Electronic Supplementary Figure S1. Images of mealy and vitreous (right and left sides of photographs, respectively) of wheat kernels: Skagen (A), Olivin (B), Ludwig (C), Muszelka (D)

Electronic Supplementary Figure $S 2$. Plate with results of Durotest ${ }^{\circledR}$ S (R-BIOFARM RHONE LTD)

Electronic Supplementary Figure S3. RP-HPLC chromatograms of albumins+globulins (1A-1D), gliadins (2A-2D) and glutenins (3A-3D) of 4 wheat cultivars: Muszelka (A), Ludwig (B), Olivin (C), Skagen (D)

Electronic Supplementary Figure S4. Characteristics of flour granulation obtained from vitreous and mealy kernels of Muszelka cultivar (Brabender Quadrumat Junior Mill) 